\title{
Rehabilitation and multiple limb amputations: A clinical report of patients injured in combat
}

\author{
Ted Melcer, PhD; ${ }^{1 *}$ Jay Pyo, DO; $^{2}$ Jay Walker, BA; ${ }^{1}$ Kimberly Quinn, RN, MSN; ${ }^{1}$ Martin Lebedda, RN; ${ }^{1-2}$ \\ Kamaran Neises, BA; ${ }^{1-2}$ Christina Nguyen, MPH; $;^{1-2}$ Michael Galarneau, NREMT, MS ${ }^{\mathbf{1}}$ \\ ${ }^{1}$ Department of Medical Modeling, Simulation, and Mission Support, Naval Health Research Center, San Diego, CA; \\ ${ }^{2}$ Comprehensive Combat and Complex Casualty Care, Naval Medical Center San Diego, San Diego, CA
}

\begin{abstract}
This clinical report describes the outpatient rehabilitation program for patients with multiple limb amputations enrolled in the Comprehensive Combat and Complex Casualty Care facility at the Naval Medical Center San Diego. Injuryspecific data for 29 of these patients wounded by blast weaponry in Afghanistan in 2010 or 2011 were captured by the Expeditionary Medical Encounter Database at the Naval Health Research Center and were reviewed for this report. Their median Injury Severity Score was $27(N=29$; range, $11-$ 54). Patients averaged seven moderate to serious injuries (Abbreviated Injury Scale scores $\geq 2$ ), including multiple injuries to lower limbs and injuries to the torso and/or upper limbs. All patients received care from numerous clinics, particularly physical therapy during the first 6 mo postinjury. Clinic use generally declined after the first 6 mo with the exception of prosthetic devices and repairs. The clinical team implemented the Mayo-Portland Adaptability Inventory, 4th Revision (MPAI-4) to assess functioning at outpatient program initiation and discharge $(n=23)$. At program discharge, most patients had improved scores for the MPAI-4 items assessing mobility, pain, and transportation, but not employment. Case reports described rehabilitation for two patients with triple amputations and illustrated multispecialty care and contrasting solutions for limb prostheses.
\end{abstract}

Key words: Afghanistan conflict, case history, case management, combat injury, functional assessment, injury severity score, multiple limb amputations, outpatient rehabilitation, physical and occupational therapy, prosthetics.

\section{INTRODUCTION}

A total of 366 U.S. combatants sustained multiple limb amputations in Iraq and Afghanistan through July of 2011 [1]. In 2010 and 2011, multiple limb amputations accounted for over 40 percent of all combat-related amputations, a substantial increase compared with 15 to 25 percent during previous years (2001-2009) [1]. These patients were among the most serious cases of recent complex battle injuries in the Afghanistan conflict, including extensive blast injuries and high-level amputations (e.g., hip disarticulation) [2-6]. Importantly, these patients present substantial new challenges for rehabilitation care providers at Department of Defense (DOD) and

Abbreviations: AIS = Abbreviated Injury Scale, C5 = Comprehensive Combat and Complex Casualty Care, DOD = Department of Defense, IED = improvised explosive device, ISS = Injury Severity Score, MDR = Military Health System Data Repository, MEPRS = Medical Expense and Performance Reporting System, MPAI-4 = Mayo-Portland Adaptability Inventory-4th Revision, NHRC = Naval Health Research Center, NMCSD = Naval Medical Center San Diego, VA = Department of Veterans Affairs.

*Address all correspondence to Ted Melcer, PhD; Naval Health Research Center, 140 Sylvester Rd, San Diego, CA 92106; 619-553-8393. Email: ted.melcer.civ@mail.mil

http://dx.doi.org/10.1682/JRRD.2014.09.0219 
Department of Veterans Affairs (VA) facilities [6]. Only one clinical report has described a rehabilitation program for individuals with multiple limb amputations [3]. The previous report was limited to one military medical center and did not quantify injuries, use and time course of rehabilitation therapies, or patient functioning [3].

The Comprehensive Combat and Complex Casualty Care (C5) program at the Naval Medical Center San Diego (NMCSD) is a DOD Extremity Trauma and Amputation Center of Excellence [7-8]. The outpatient program was developed based on DOD/VA clinical guidelines [8]. A unique feature of the program is integration and access to medical and nonmedical specialty services with the focus on reconstruction, rehabilitation, and reintegration of the severely injured servicemember. In 2010 and 2011, the program treated 40 patients who had sustained multiple limb amputations during combat operations in Afghanistan.

The rehabilitation facility was initially renovated in 2006 to enhance collaboration among specialty clinics, care coordination, and patient access. The prosthetics laboratory provided on-site fabrication, fitting, and repair of conventional and advanced prostheses. The gait clinic conducted a regular series of biomechanical measures of ambulation. These tests were conducted after initial ambulation using prosthetics with follow-ups at $6 \mathrm{wk}$, $3 \mathrm{mo}, 6 \mathrm{mo}, 12 \mathrm{mo}$, and annually thereafter as patients were available. The physical therapy team implemented a phased sports/combat rehabilitation protocol [8]. Patients had access to modern equipment and adaptive applications (e.g., a therapy pool for low-impact resistance and aerobic conditioning) based on injury level and functional ability. Prosthetic training was conducted using “weightless gait trainers” (e.g., Solo-Step, Inc; North Sioux City, South Dakota) to prevent falling. Patients wore a suspension harness attached to an overhead track, which supported their body weight in the event of a fall. The harness or weightless gait trainers were used as needed to assist individuals who presented high risk of falls or who required graduated transition from supported ambulation (i.e., parallel bars and walkers) to unsupported ambulation without the use of an assistive device. Our informal observation was that use of the harness system/weightless gait trainers was more prevalent among people with bilateral lower-limb amputations than among people with unilateral lower-limb amputations. It also served as a training/safety tool to stabilize balance and weight bearing.
In addition, the physical therapy resources included variable resistance strength training platforms and a $30 \mathrm{ft}$ climbing wall to promote agility, muscle strengthening, balance/vestibular training, and upper- and lower-body coordination. A multiterrain obstacle course included ramps (inclines and declines), stairs, and beams as well as sand, gravel, rock, and brick terrains to simulate surfaces encountered in everyday communities. The wall was also utilized by recreation therapy and outdoor climbing programs and was a resource for individuals with lower-limb amputations, including some with bilateral lower-limb amputations. In this case, our informal observation was that use of the wall was more prevalent among patients with single lower-limb amputations than among individuals with bilateral lower-limb amputations. The wall was also used by patients with other injuries or conditions such as traumatic brain injury and posttraumatic stress disorder.

The occupational therapy clinic included a simulated home, kitchen, and driving environment and collaborated with the cognitive rehabilitation team on upper-limb rehabilitation to master activities of daily living and instrumental activities of daily living in the home. Patients were also trained for use of public transportation, public land, and water parks and at local military facilities for highperformance activities including combat simulations as appropriate. The patients' care team coordinated access to these facilities, which were all located within a $50 \mathrm{mi}$ radius of NMCSD/C5.

The centralized facilities in particular promoted interaction and camaraderie between patients, who frequently conducted their rehabilitation work side-by-side; enhanced family and community reintegration goals; and helped identify potential for return-to-active-duty goals. Accessible living quarters for the injured servicemembers, caregivers, and/or family were located on the campus of NMCSD within several hundred yards of the rehabilitation facilities. All patients were assigned a primary care provider and a nurse case manager to coordinate a multidisciplinary plan of care and timely appointments across various departments. All patients received a mental health screening at program entry and follow-up psychological or psychiatric care as appropriate. Recreation therapy provided community reintegration planning using bodypowered prostheses and myoelectric prostheses, access to adaptive sports, and access to health and wellness programs including nutrition counseling and fitness training programs. Finally, the nurse case managers, transition counselors, and VA liaisons coordinated each patient's 
medical evaluation board for military discharge transition to postmilitary life and facilitated transition to VA healthcare. Local community partner programs provided access to community resources for job and career development opportunities.

The objectives of this report are to (1) describe clinical experiences and practices of the rehabilitation program for patients with multiple limb amputations; (2) quantify injuries, clinic use, and patient functioning for a small sample of such patients undergoing rehabilitation; and (3) provide detailed case reports of two patients with triple amputations. This information can illustrate novel aspects of the injuries and rehabilitation (e.g., prosthetic fitting) for patients with recent multiple limb amputations to help future military, VA, and civilian providers better understand early rehabilitation histories and to optimize patient care plans.

\section{METHODS}

\section{Patients}

A total of 40 patients in the C5 program had at least two major limb amputations following combat injury in the Afghanistan conflict in 2010 or 2011. The treating physiatrist invited by telephone or by email 36 of these 40 patients to participate in person at NMCSD. (The remaining four patients did not have contact information available.) The physiatrist provided each individual with a one-page project summary and the consent form and answered any questions. Of 36 patients who were invited to participate, 29 individuals provided free and informed written consent to have their medical records reviewed.

\section{Outcome Measures}

\section{Abbreviated Injury Scale and Injury Severity Score Metrics}

The Expeditionary Medical Encounter Database, maintained by the Naval Health Research Center (NHRC), contains information abstracted from U.S. servicemembers' casualty records completed by military providers at forward deployed treatment facilities in the combat zone beginning within hours of injury [9]. Casualty records for the 29 patients in this study were reviewed by certified nurse coders at NHRC who assigned Abbreviated Injury Scale (AIS) score and Injury Severity Score (ISS) metrics [10].

The ISS is an anatomical scoring system that provides an overall score for patients with multiple injuries
[10]. Each injury is assigned an AIS score from 0 to 6. A score of 6 is usually not survivable. Each AIS score is assigned to one of six body regions (i.e., head, face, chest, abdomen, limbs, or external). The highest AIS scores in the three most severely injured body regions are used to calculate the ISS metric [10].

\section{Clinic Use}

The Military Health System Data Repository (MDR) contains records of healthcare encounters from all U.S. military medical facilities. We extracted clinic visits that occurred at NMCSD for the 29 patients. The MDR includes the Medical Expense and Performance Reporting System (MEPRS) data that identified the postinjury timing and frequency of visits for various clinics (e.g., physical therapy, occupational therapy). The MDR also stores Current Procedure Terminology L-codes for limb prostheses and/or associated repairs for these devices. To simplify the presentation, we grouped one or more of the individual MEPRS codes into broader categories as follows: physical therapy (i.e., physical therapy, physical medicine, pain management, ambulatory rehabilitation services, physical medicine ward, and neurology), social work (i.e., social work and community health), primary care (i.e., primary care and internal medicine), orthopedic (i.e., orthopedics, orthopedic ward, and orthotic laboratory), surgery (i.e., general surgery ward, plastic surgery, and general surgery), and mental health (i.e., mental health, psychiatric, and psychology). Occupational therapy, infectious disease, nutrition, and urology each represented its own category.

\section{Functional Assessments}

The Mayo-Portland Adaptability Inventory-4th Revision (MPAI-4) was designed to assess the abilities and outcomes of patients with acquired brain injury during outpatient rehabilitation [11]. This instrument includes 35 items that can be completed in $20 \mathrm{~min}$. There are multiple items in three functional areas: (1) physical abilities (e.g., mobility, use of hands, speech), (2) adjustment issues (e.g., irritability, anxiety, depression), and (3) social interactions and community participation (e.g., recreation, employment) [11]. Each item is rated on a scale of raw scores ranging from 0 (no problems) to 4 (interferes with activity more than $75 \%$ of the time). Raw scores can be converted to $t$ scores (using conversion tables in the MPAI-4 manual [11]) for reference to previously tested patient samples with acquired brain injury. The scores can be assigned by 
rehabilitation professionals and/or patients and significant others [12-13]. The manual provides detailed guidelines for its use, including assigning scores for specific items (e.g., mobility). It has been refined repeatedly since 1994 to improve its psychometric properties and is currently in its fourth revision. Kean et al., Malec, and the MPAI user manual demonstrate its satisfactory psychometric properties including reliability and internal consistency for ratings provided by patients, their significant others, or rehabilitation providers [11-14]. The MPAI-4 has satisfactory construct, concurrent, and predictive validity for acquired brain injury populations in outpatient settings. In summary, Kean et al. emphasize that the MPAI-4 meets important goals of "clinical relevance, usability, and psychometric quality" content to assess a broad range of physical and psychosocial outcomes [12].

The clinical team had established clinical goals for improving physical and psychosocial functioning. Although the MPAI-4 has not been validated for patients with amputations, this instrument was used to assess these goals for several reasons. First, it assessed the broad range of clinical content areas for outpatient rehabilitation following amputation, namely physical mobility, adjustment issues, and participation. Second, this instrument helped the clinical team document and coordinate each patient's progress and update care plans as appropriate during team meetings (described in a later section). Third, the instrument was completed in a relatively short time, approximately 15 to 20 min per patient. In short, the clinical team's judgment was that this instrument had face and content validity for assessment of functional outcomes following multiple limb amputations. They selected the MPAI-4 because it provided a more comprehensive assessment of physical and psychosocial issues over other measures (e.g., Oswestry Disability Index, Functional Independence Measure [15-16]).

\section{Research Design}

This was a retrospective analysis of existing health data. The MPAI-4 was completed for each patient at C5 outpatient program initiation and again at program discharge. Use of outpatient clinics was followed for up to $18 \mathrm{mo}$. There was some variability in follow-up times for functional assessments and clinic use because patients completed outpatient rehabilitation and then transitioned to VA health care at different times (as described in the Results section). They were lost to follow-up because we did not have access to VA medical records.

\section{Procedures}

The following was the standard procedure for completing MPAI-4 forms for each patient at program initiation and discharge. First, the treating providers in each of 11 departments assigned preliminary scores based on their clinical experience with each patient. The 11 departments were physiatry, primary care, physical therapy, occupational therapy, prosthetics, social work, case management, primary care, recreation therapy, speech therapy, and mental health. With few exceptions, the patients had the same providers throughout outpatient rehabilitation because there was very little turnover among providers and department heads. Second, the treating providers from each department presented preliminary scores at case conferences. Each patient's scores were represented by another department member if the treating provider could not be present. Third, all scores were discussed and a final score was determined by consensus and assigned at the end of the case conference. Raw scores and $t$-score calculations were generated. Finally, a timeline for follow-up case reviews, midterm and discharge MPAI-4 scoring timelines, and anticipated discharge was established at the initial case conference. The total time to finalize all scores for each patient at a case conference was 15 to $20 \mathrm{~min}$.

The clinical team assigned raw scores to MPAI-4 items relative to each patient's potential level of functioning given his or her amputations (rather than relative to an uninjured individual). For example, a patient with bilateral transfemoral amputations who ambulated using prosthetic limbs (with or without a cane) by program discharge received a raw score of 1 or 0 (little or no functional impairment) on the mobility item.

Case reports were based on interviews with the treating physiatrist who managed day-to-day care of each patient. We reviewed patient injuries, treatments, and electronic progress notes recorded by providers.

\section{Data Analysis}

Descriptive analyses (means and medians) summarized the demographic and injury characteristics $(N=$ 29). The data on clinic use $(N=29)$ was summarized by counting the number of patients who visited specific clinics during the first six quarters or through 18 mo postinjury (each quarter $=90 \mathrm{~d}$ ). We also calculated the median number of visits during the first six quarters for each clinic (excluding patients with no visits).

We analyzed MPAI-4 raw scores for the present study because the $t$-score conversions were based on patients 
with acquired brain injury rather than limb amputations. Use of raw scores also provided results for key items such as mobility, use of the hand, and psychosocial items (e.g., anxiety/depression, transportation, employment). Frequency distributions were used to summarize MPAI-4 raw scores at program initiation and discharge for the 23 patients who had completed functional assessments at both initiation and discharge. Of the six patients with missing functional assessments, four were a result of lost paperwork and two did not complete the rehabilitation program. Of the two patients who did not complete the program, one was noncompliant with providers and the other was functioning well and left the program early.

\section{RESULTS}

\section{Injury Characteristics}

The 29 patients were between 20 and 31 yr of age (mean, 25; median, 24) and had sustained blast-related injuries from an improvised explosive device (IED). The mean and median ISSs (28 and 27, respectively range 11-54) indicated patients sustained multiple moderate to serious injuries. Twenty-five of the patients had an ISS greater than 20. Seven patients had triple amputations, which included partial hand/foot loss. The remaining 22 patients had double amputations, all with bilateral lower-limb loss. Most patients with double amputations (19 of 22) had transfemoral amputations and/or hip disarticulation(s). We included partial hand/foot amputations because they can significantly affect functional outcomes given a patient's other major limb amputations. On average, the 29 patients had more than seven moderate to serious injuries (AIS $\geq 2$; Table 1), including multiple injuries to the lower limbs. The majority of patients also had multiple injuries to the torso and/or upper limbs. Other than amputations, fractures, internal injuries, and open wounds were the predominant injury types.

\section{Clinic Use}

All 29 patients visited each of the outpatient clinics shown in Table 2 at least once, except for surgical ( $n=$ $28)$, nutrition $(n=22)$, urology $(n=19)$, and infectious disease $(n=10)$ treatment. The table shows the number of patients who used various clinics at least once, by quarters, after injury. Nearly all patients used physical therapy during each of the first six quarters. Similarly, the majority of patients used orthopedics, primary care, and social work clinics during the first six quarters. There was a general decline in numbers of patients using clinics over time. The exception was that there were increased numbers of patients with prosthetic devices or repairs over the first four quarters, and numbers remained high thereafter.

Figure 1 shows the median number of visits per patient over time for various clinics $(N=29)$. The medians for each quarter included only patients with at least one visit. For all clinic activity combined, there were more than 100 visits per patient during each of the first two quarters (more than one per patient per day). Thereafter, the median scores declined steadily over time (Figure 1(a)). Figures

Table 1.

Injury types and locations for moderate to serious injuries (Abbreviated Injury Scale score $\geq 2$ ) sustained by patients with multiple limb amputations.

\begin{tabular}{|c|c|c|c|c|c|c|}
\hline \multirow[b]{2}{*}{ Injury } & \multicolumn{5}{|c|}{$\begin{array}{c}\text { Injury Type } \\
\text { (No. of Patients/Mean No. of Injuries) }\end{array}$} & \multirow{2}{*}{$\begin{array}{c}\text { Total } \\
(N=29)\end{array}$} \\
\hline & Fracture & $\begin{array}{l}\text { Open Wound, } \\
\text { Crush }\end{array}$ & Amputation & Internal & $\begin{array}{l}\text { Dislocation, } \\
\text { Sprain, } \\
\text { Superficial }\end{array}$ & \\
\hline \multicolumn{7}{|l|}{ Location } \\
\hline TBI & - & - & - & $1 / 1.0$ & - & $1 / 1.0$ \\
\hline Other Head, Neck, Face & $1 / 1.0$ & - & - & $2 / 1.0$ & $1 / 1.0$ & $4 / 1.0$ \\
\hline Spine and Back & $5 / 1.6$ & - & - & - & - & $5 / 1.7$ \\
\hline Torso & $6 / 1.3$ & $20 / 1.6$ & - & $12 / 2.0$ & $1 / 2.0$ & $23 / 2.9$ \\
\hline Upper Limb & $14 / 2.1$ & $4 / 1.2$ & $7 / 1.1$ & $3 / 1.7$ & $2 / 1.0$ & $19 / 2.6$ \\
\hline Lower Limb & $10 / 1.7$ & $7 / 1.1$ & 29/1.6 & $4 / 1.3$ & $1 / 1.0$ & $29 / 2.7$ \\
\hline Total $(N=29)$ & $23 / 2.7$ & $23 / 2.0$ & 29/1.9 & $15 / 2.5$ & $3 / 2.0$ & 29/7.1 \\
\hline
\end{tabular}

Note: Abbreviated Injury Scale scores $\geq 2$ indicate moderate or serious injuries to specific body regions. 
Table 2.

Patients with at least one clinic visit during consecutive quarterly intervals (90 d) after injury $(N=29)$.

\begin{tabular}{|c|c|c|c|c|c|c|}
\hline \multirow{2}{*}{ Clinic } & \multicolumn{6}{|c|}{ Quarters after Injury } \\
\hline & 1 & 2 & 3 & 4 & 5 & 6 \\
\hline Any Clinic & 26 & 29 & 29 & 29 & 29 & 28 \\
\hline Physical Therapy & 26 & 28 & 29 & 29 & 29 & 27 \\
\hline Occupational Therapy & 25 & 28 & 28 & 19 & 13 & 11 \\
\hline Social Work & 24 & 22 & 22 & 18 & 19 & 18 \\
\hline Surgical $(n=28)$ & 25 & 16 & 12 & 10 & 4 & 5 \\
\hline Orthopedic & 25 & 28 & 29 & 28 & 24 & 24 \\
\hline Primary Care & 24 & 29 & 28 & 26 & 20 & 16 \\
\hline Mental Health & 19 & 19 & 12 & 12 & 9 & 4 \\
\hline Nutrition $(n=22)$ & 21 & 7 & 8 & 5 & 2 & 2 \\
\hline Urology $(n=19)$ & 15 & 8 & 6 & 6 & 2 & 4 \\
\hline Prosthetic Devices/Repairs ${ }^{*}$ & 8 & 17 & 22 & 24 & 26 & 25 \\
\hline Infectious Disease $(n=10)$ & 6 & 4 & 4 & 4 & 1 & 3 \\
\hline $\begin{array}{l}\text { Note: Except where noted, all } 29 \\
\text { least one quarter. } \\
{ }^{*} \text { Based on Current Procedure Tern }\end{array}$ & tien & si & & & & \\
\hline
\end{tabular}

1(b) through 1(d) show the median visits per patient separately for various clinics. Physical and occupational therapy showed the highest frequencies of visits per patient, particularly during the first two quarters. For most clinics, frequency of use generally declined after the first several quarters. The primary exception was that the number of prosthetic devices and/or repairs increased over time. There were also slight increases in median visits per patient for mental health, nutrition, and social work. (These results are limited to frequency of visits, and the duration/intensity of visits may vary for different clinics.)

\section{Functional Assessments}

For the 23 patients (four with triple amputations and 19 with double amputations) with completed MPAI-4 data, the median time between program initiation and discharge assessments was 12 mo (range, 7-19 mo). Figures 2 and 3 show the distribution of raw scores for MPAI-4 items assessing various abilities (e.g., mobility, use of hand) and participation items (e.g., leisure and recreation, family interaction, transportation). Compared with program initiation, the raw scores generally indicate improved functioning at program discharge. This was particularly true for mobility (19 of 23 improved), transportation (18 of 23 improved), leisure and recreation (20 of 23 improved), and pain (17 of 23 improved). For selfcare, 16 of 17 patients who had at least some limitation (i.e., raw scores $\geq 1$ ) improved by program discharge. For use of the hand, 11 of 12 patients who had at least some limitation (i.e., raw scores $\geq 1$ ) improved by program discharge. By contrast, only 6 of 23 patients improved scores in paid/other employment.

The MPAI-4 items assessing adjustment issues, such as irritability, anxiety, and depression, generally indicated most patients had no or minor impairments (raw scores = 0 or 1) at program initiation (data not shown). At program initiation, 14 of 23 patients had at least some irritability, including 11 raw scores of 1 . Of these 14 patients, 9 had decreased scores for irritability at program discharge (only 1 individual had an increased score). For anxiety, 12 of 23 patients started the program with at least some anxiety, including four individuals with mild or moderate impairment (raw scores $\geq 2$ ). Of these 12 patients, 9 had decreased scores at discharge (only 1 patient had an increased anxiety score). For depression, 9 of 23 patients started the program with at least some depression. Of these nine, six individuals had decreased scores for depression at program discharge (only 1 patient had an increased depression score). Finally, the increased scores we noted for irritability, anxiety, and depression at program discharge came from the same patient in all three cases.

\section{Case Reports}

These case reports describe two of the most challenging patients in our cohort. We chose these cases to illustrate the range of care issues encountered during outpatient rehabilitation, such as the potential for functional independence, application of conventional and advanced upper- and lower-limb prostheses, and strategies to optimize mobility and functioning for patients with multiple major limb loss. These cases provide examples of the basic phases of rehabilitation, including (1) pre-, peri-, and postsurgical care; (2) preprosthesis rehabilitation; (3) prosthesis training for functional mobility; (4) advanced prosthesis training; and (5) development of a health and wellness program.

\section{Case 1}

This patient was a 21-yr-old right-hand-dominant male enlisted servicemember. He sustained injuries from an IED while deployed in Afghanistan in late 2010. He transferred to NMCSD approximately 2 mo postinjury and completed his MPAI-4 functional assessments at program initiation and at program discharge 14 mo later. 
(a)

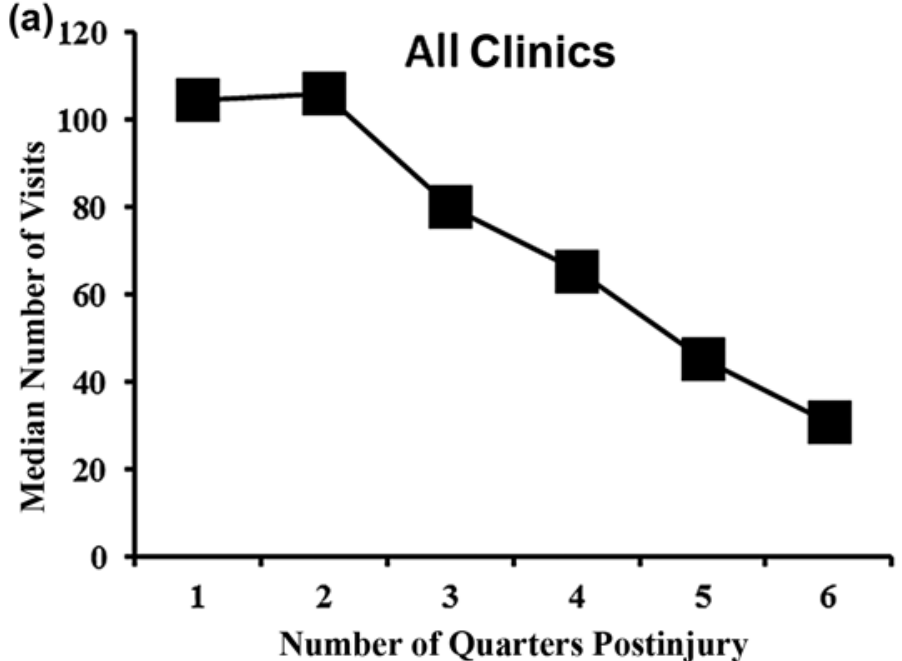

(c)

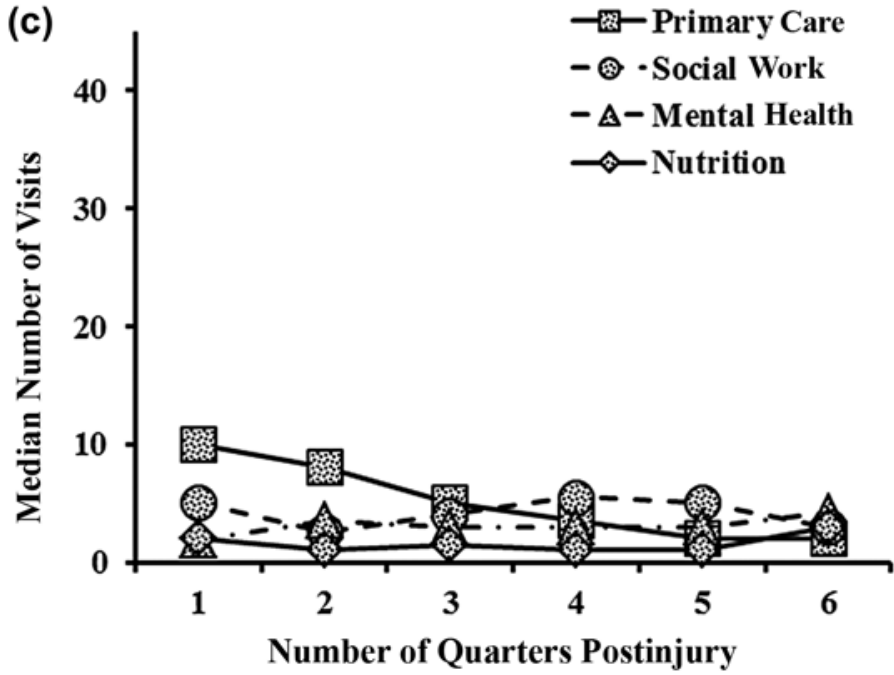

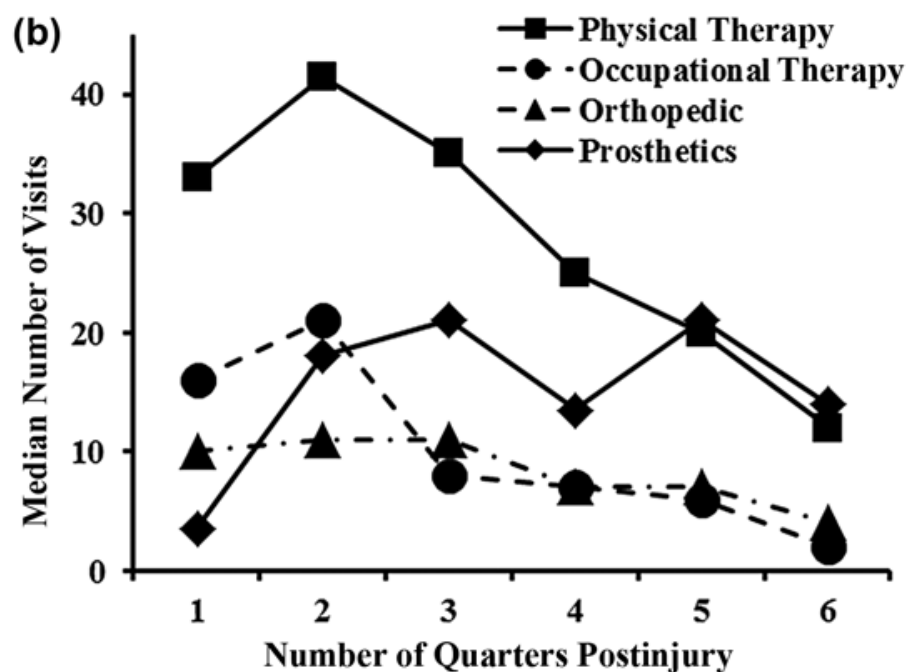

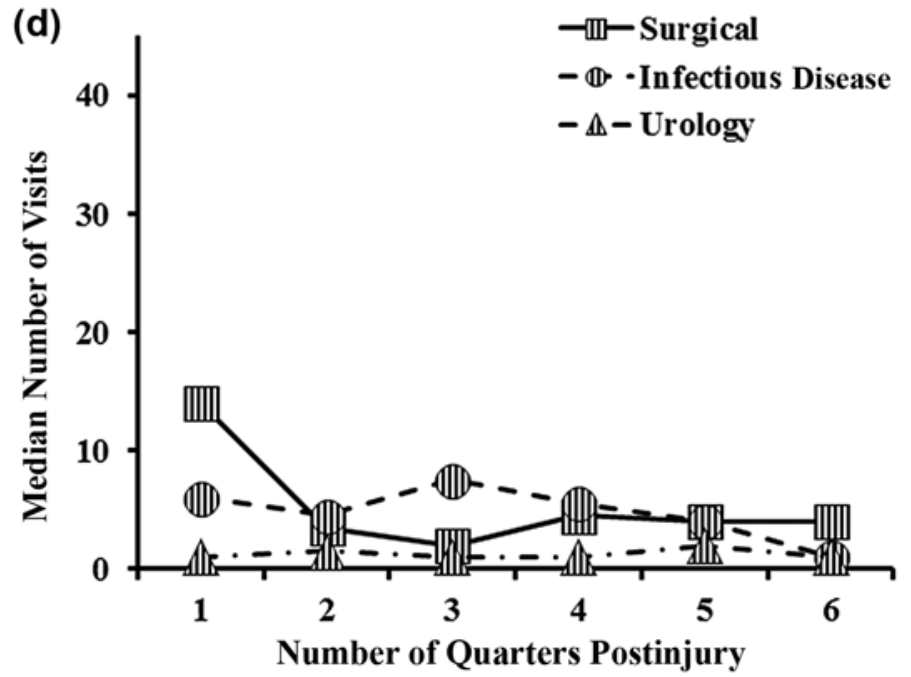

Figure 1.

Median number of clinic visits per patient $(N=29)(\mathbf{a})$ across all clinics and $((\mathbf{b})-(\mathbf{d}))$ for individual clinics during the first six quarterly intervals (90 d each) postinjury. The median scores are based on the number of patients with at least one clinic visit during each quarter (Table 2).

The patient had three limb amputations, including a left hemipelvectomy, right transfemoral amputation, and disarticulation of digits $2-5$ on the left hand. This patient's ISS was 29 as a result of a serious (AIS $=3$ ) lung contusion and several moderate injuries (AIS $=2$ ), including a pubis fracture, open wound of the scrotum, bilateral testicular rupture with left epididymis injury, closed lumbar fracture, and multiple penetrating wounds to the right and left forearms. The patient had substantial radiographic evidence of heterotopic ossification in the left hip and minimal heterotopic ossification at the distal right femur, but neither location required surgical excision. Heterotopic ossification in the left hip did not cause significant pain with prosthesis use and provided some benefit for prosthetic suspension [17]. This patient also gained significant weight postinjury, which presented additional limitations to his mobility.

Lower-limb prosthesis management. This patient was fitted with short prosthetic legs, also called "shorties," as transitional devices to initiate prosthesis training $90 \mathrm{~d}$ after injury [3]. The short length and relatively low weight of these devices allow patients to safely develop basic 
(a)

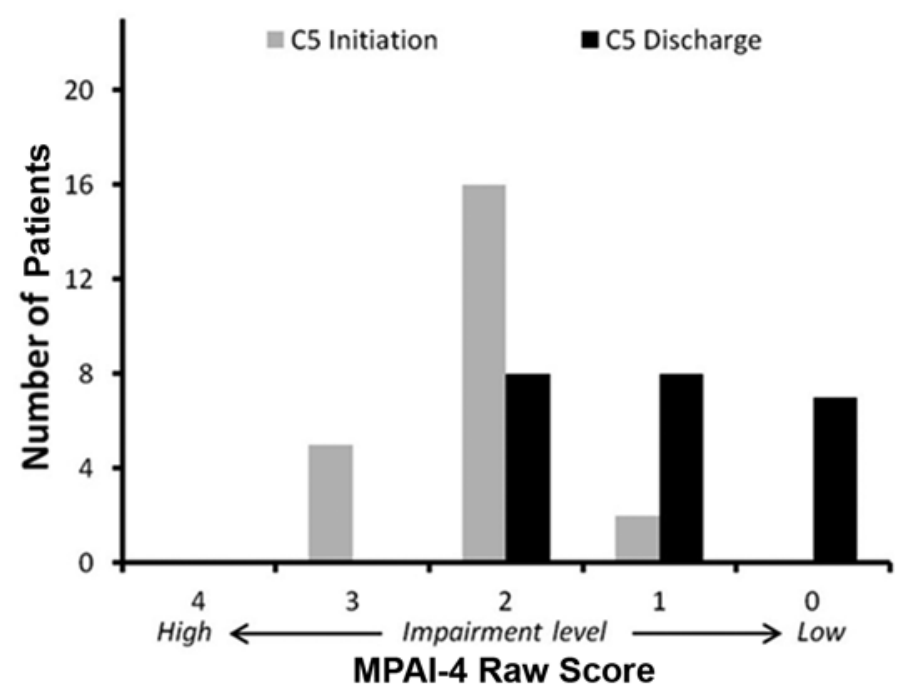

(c)

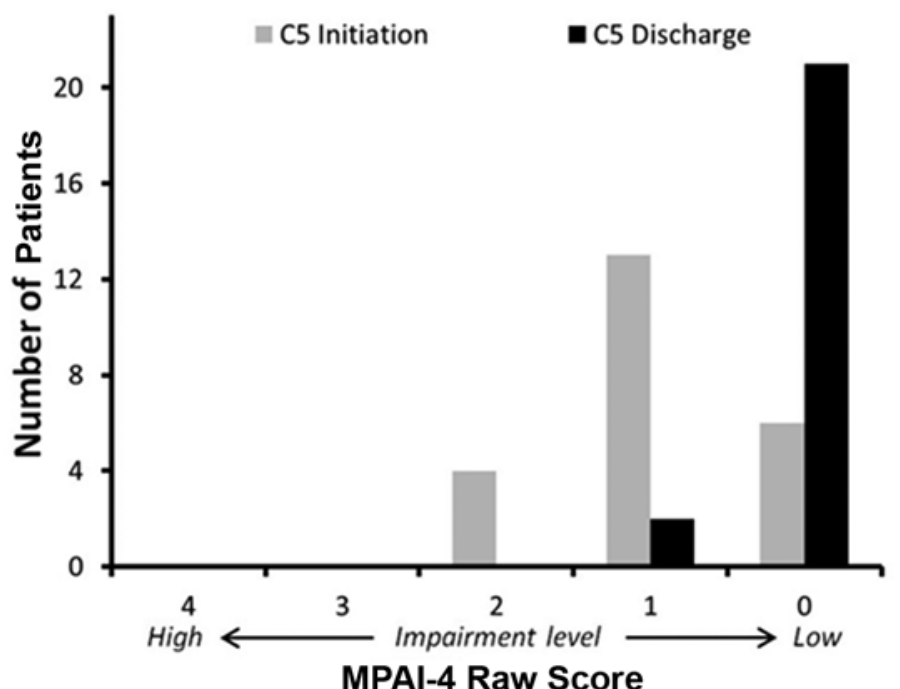

(b)

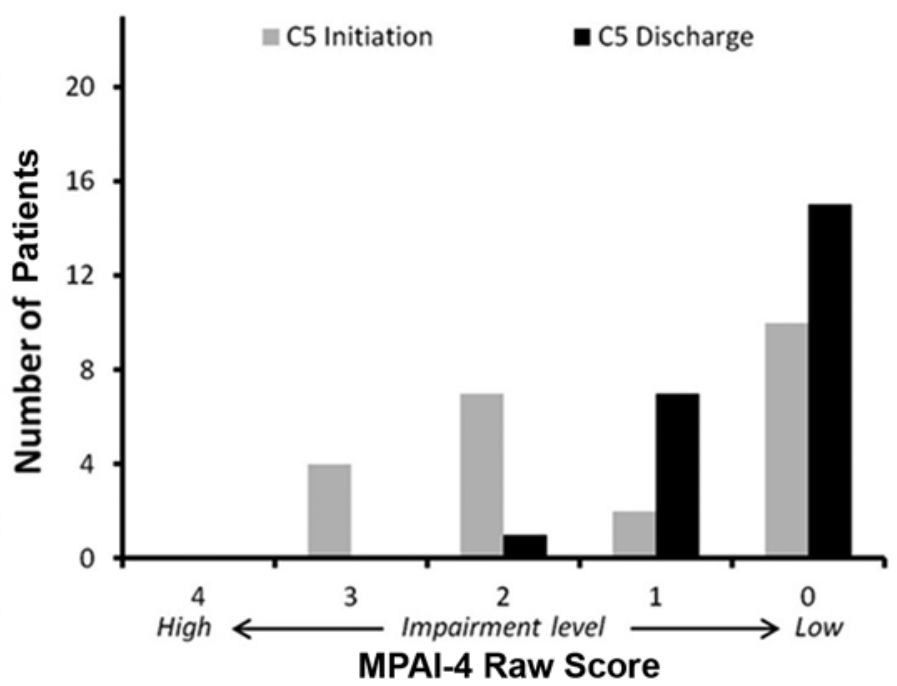

(d)

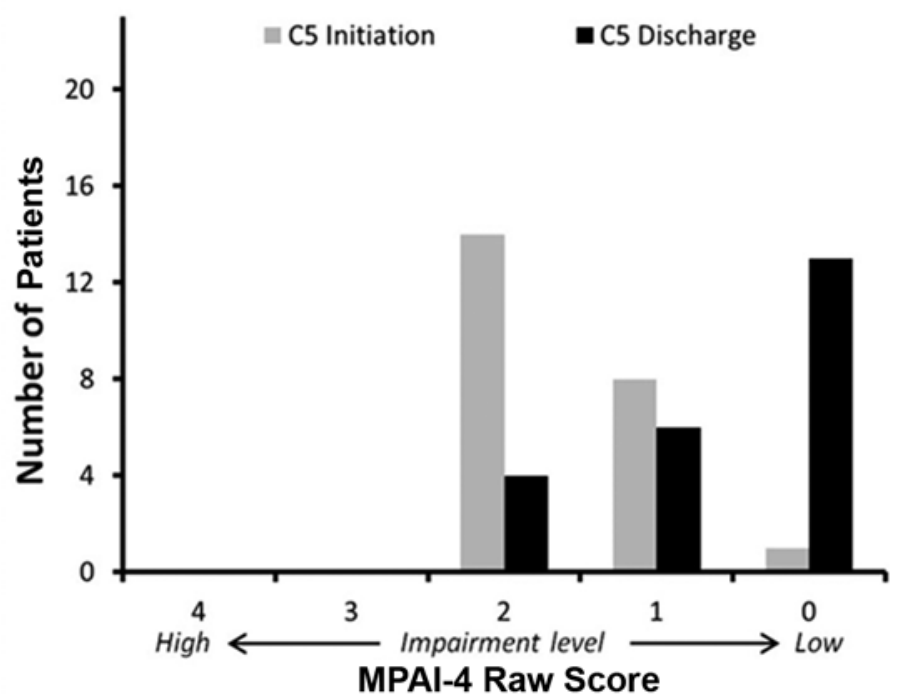

Figure 2.

Frequency of patients $(n=23)$ at program initiation and discharge with Mayo-Portland Adaptability Inventory-4th Revision (MPAI-4) raw scores for the (a) mobility, (b) use of hand, (c) self-care, and (d) pain and headache items. MPAI- 4 raw scores: $4=$ impairment interferes with activity $>75 \%$ of the time; $3=$ impairment interferes with activity $25 \%-50 \%$ of the time; $2=$ impairment interferes with activity $<25 \%$ of the time; $1=$ impairment does not significantly interfere with activity; $0=$ no impairment. C5 = Comprehensive Combat and Complex Casualty Care.

prosthesis skills and muscular endurance to facilitate transition to full-length prostheses. This patient used shorties on both legs with platform feet and a custom sole, which consisted of a prefabricated rectangular polycarbonate base with a rubber sole. They were selected as training devices because of their stable base. The patient used the shortie legs and platform feet along with a hemi walker (with lefthand support) for assistance. The patient progressed to $6 \mathrm{~h} /$ $\mathrm{d}$ of independent ambulation on shorties over the first 4 mo of initial gait training. These prosthetic legs were progressively lengthened as training for full-length prostheses. In general, our guideline is to begin lengthening shorties when 
(a)

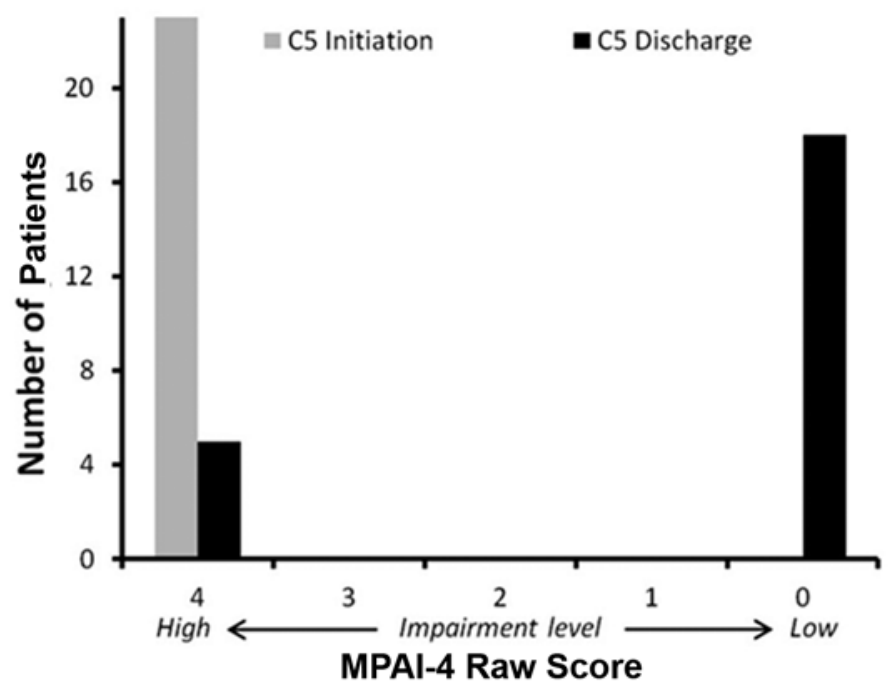

(c)

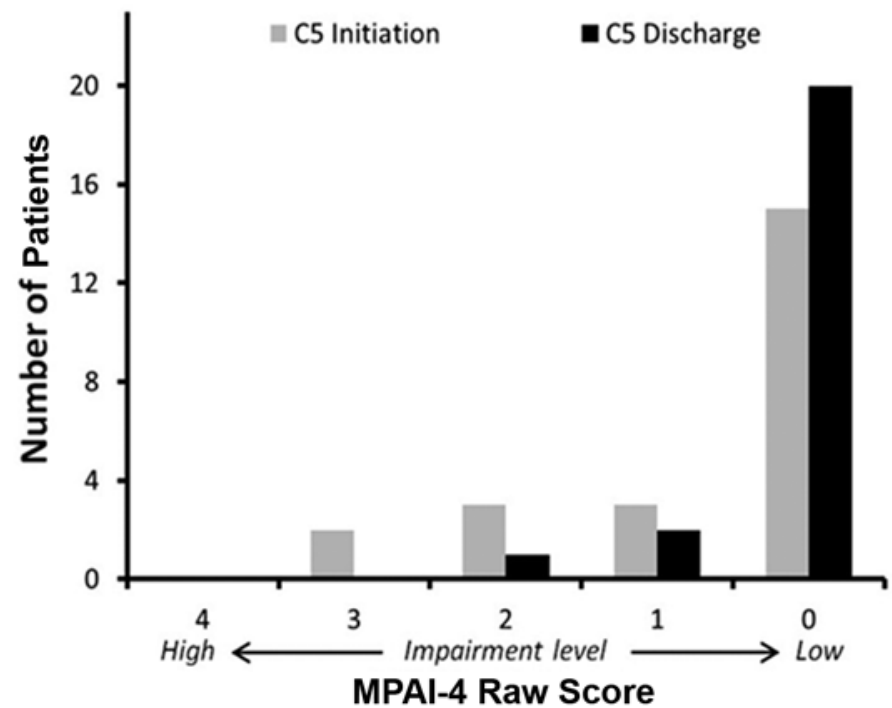

(b)

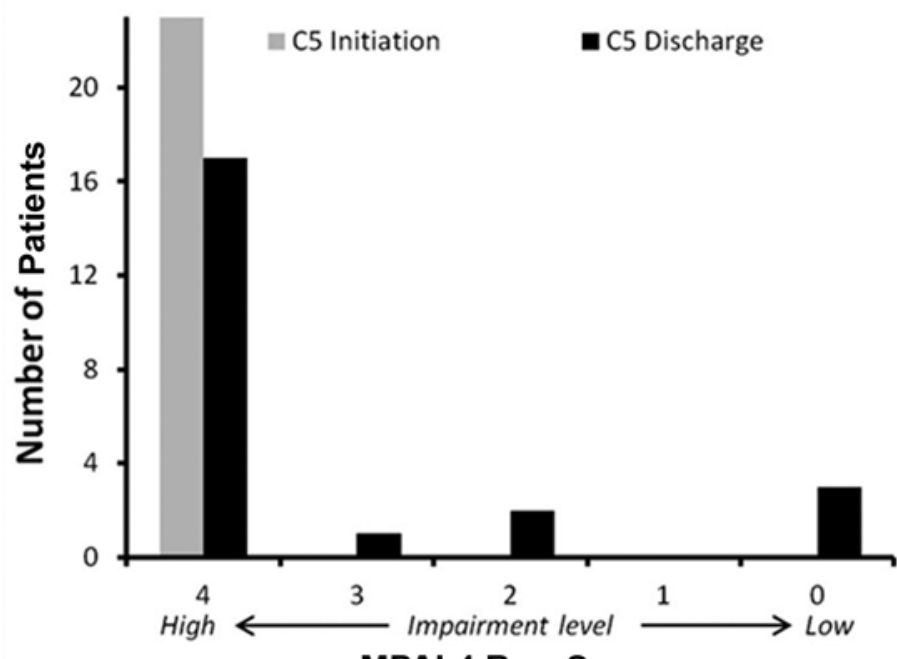

(d)

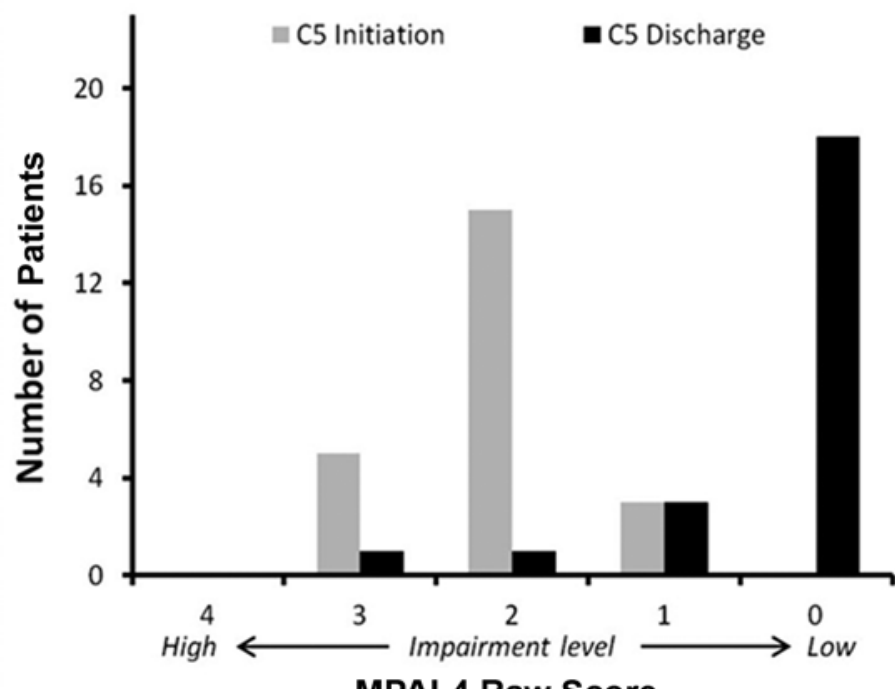

Figure 3.

Frequency of patients $(n=23)$ at program initiation and discharge with Mayo-Portland Adaptability Inventory-4th Revision (MPAI-4) raw scores on the (a) transportation, (b) paid/other employment, (c) family/significant other relationships, and (d) leisure/recreational activities items. MPAI-4 raw scores: $4=$ impairment interferes with activity $>75 \%$ of the time; $3=$ impairment interferes with activity $25 \%-50 \%$ of the time; 2 = impairment interferes with activity $<25 \%$ of the time; $1=$ impairment does not significantly interfere with activity; $0=$ no impairment. C5 = Comprehensive Combat and Complex Casualty Care.

the patient can independently ambulate functional distances (approximately 300-500 ft) with or without use of an assisted device. The device is gradually lengthened until the prosthesis is compatible with the addition of a standard knee and foot component. We then conduct trials with different knee components, which continue as long as the patient is able to ambulate independently with or without an assistive device.

In efforts to work toward community reintegration goals and the patient's desire to ambulate with knee units, the second prosthesis design was bilateral C-Legs (Ottobock USA; Minneapolis, Minnesota) and Variflex feet 
(Össur Americas; Foothill Ranch, California). This patient worked with these devices $1-3 \mathrm{~h} / \mathrm{d}$ to develop balance and ambulation skills. A C-Leg was chosen because of its programming system, hydraulic-based knee action, and relative safety (for stance control) and durability.

He was not seen as a candidate for the X2 microprocessor knee (Ottobock USA) because of his left hemipelvectomy, right transfemoral amputation, and poor upperbody control as a result of loss of command function in his left hand. These high-level amputations limited his ambulation potential to short distances on level surfaces. Therefore, he was predicted to have very limited ability as a functional ambulator. Specifically, we expected he would be able to ambulate with nonvariable cadence only on flat and even surfaces. We did not anticipate that he would use the prosthesis in inclement environments (e.g., mud, water, snow, sand). Also, we were experiencing significant prosthesis failures with the X2 knees with other patients during this time period. Our criteria for prescription of the X2 knee required transfemoral amputations with potential for high-level activity and ambulation. By contrast, the C-Leg was a more reliable device for stance control and programmable knee flexion movements. The hypothesis generated by the care team was that a power knee would supplement functioning of the limb caused by the loss of his hip.

The Variflex feet were selected for all initial ambulation trials because of their dynamic multiaxial action properties, which promote stance stability and provide the capability to accommodate excessive ground reaction forces because of hip rotation and trunk lean. The patient's functional mobility with regard to ambulation distance and patient effort did not improve clinically with this design after a 2 mo trial with the C-Leg. Therefore, the providers conducted a subsequent trial with a power knee.

The experimental trial was conducted with an advanced version of the Power Knee (Össur Americas). This device provides powered knee flexion and extension, which can assist patients with transfemoral amputations to increase total walking distance, stand up from a seated position, and climb stairs. The prosthetist can program dynamic adjustments in the Power Knee to customize walking efficiency. The rehabilitation team hypothesized that this device would reduce excessive trunk movements (i.e., rotation and lateral lean). We have observed these movements frequently in motion analyses conducted in our gait clinic for individuals with bilateral transfemoral amputations ambulating with these prosthetic knee com- ponents. We hypothesized that the Power Knee would supplement function of the lost left hip joint. After a 3 mo trial, providers determined that the Power Knee was not an ideal device because the force of the knee's action, once activated, caused increased trunk instability, particularly on the hip disarticulation side. Furthermore, the patient could not tolerate the weight of the knee, which also caused limitations with balance and trunk stability, comfortable socket fit, and socket suspension.

The final functional prosthesis design was a modified shortie prosthesis with a single-axis hip joint on the left leg and bilateral manual locking knees attached to dynamic carbon fiber feet. These conventional devices allowed the patient to ambulate with the circumduction gait learned during initial prosthesis training. The manually locking knees were easily unlocked to form a $90^{\circ}$ angle at the knee joint, which facilitated transfer into a vehicle in a seated position. The combination of the dynamic feet and knees in the locked position allowed this patient to use commercially available shoes (e.g., tennis shoes). The lightweight components, dynamic foot response, and increased ease of socket management facilitated ambulation. In the opinion of the rehabilitation physicians, these manual locking devices also promoted development of supporting musculature for walking in the long term. The advantage of adding manual locking knees, as an adaptation to their shortie prostheses, is that they allow patients to stand and ambulate (locked) and then sit in a chair or wheelchair (unlocked) without having to remove the shortie prosthesis. This solution with the manual locking knee was more practical to transition back and forth from walking to sitting throughout the day. We have observed that walking on shorties aids in the development of strength and conditioning of proximal thigh and hip musculature and pelvic stabilization musculature. The functional outcomes and stability while walking with these manual devices were superior to previous options attempted for this patient. This was also the system preferred by the patient. He was independent with a wheelchair and was able to use his shortie legs for functional mobility tasks limited to short distances.

Upper-limb prosthesis management. Preprosthesis management of the patient's left hand was complex and time intensive and involved multiple medical services. The patient presented with joint contracture and limited active and passive range of motion at the wrist and thumb. Over the course of 6 mo of intensive hand therapy, he regained painless and functional range of motion 
of the left wrist and thumb at the metacarpophalangeal and interphalangeal joints. He was able to oppose the thumb to the region of the middle finger. Initially, a thermoplastic wrist splint with a finger-like projection (i.e., forefinger substitute) allowed a pinch grip between the thumb and the end of the splint. This device was the initial prosthetic hand and was used as a training device.

The plastic surgery team subsequently completed surgical debulking of the hand flap to accommodate fit and suspension of a silicone liner and socket system for a prosthetic hand. The patient was fitted with a myoelectric device that allows for customization of finger alignment (ProDigits, Touch Bionics; Mansfield, Massachusetts). The device processes muscle movements, electronically controls prosthetic fingers to open or close, and can be used if motion is available from a remnant digit to operate the sensors. The socket was fit to maximize range of motion of the patient's thumb, and the ProDigits fingers were laminated onto a wrist/hand socket. This preserved the patient's pinch grip and gross motor cylindrical grasp. The patient used this device for fine and gross motor activities of daily living, such as grasping kitchen utensils.

At program discharge, the patient had met his goals for independent self-care, controlling pain without medication, and driving an adapted vehicle. At 18 mo postinjury, he continued involvement in leisure and recreational activities (e.g., hand cycling, swimming, adaptive surfing) and improved psychological adjustment to his new lifestyle. He used a powered wheelchair more than 50 percent of the day and the manual locking prosthetic legs primarily within the household for short-distance tasks and during exercise and maintenance therapies. He ultimately rejected the hand prosthesis because he was able to perform basic manual tasks more efficiently without the device. The patient used adaptive gloves equipped with a wrist cuff to stabilize his wrist and effectively grasped and held free weights and operated a hand cycle. At the last follow-up, this patient received medical retirement from military service and moved to his hometown in a rural area where he was considering returning to school. The transition team facilitated transfer for medical and prosthesis management through his local VA.

\section{Case 2}

This patient was a 22-yr-old right-hand-dominant male enlisted servicemember. He sustained blast injuries from an IED while deployed in Afghanistan in 2011. He transferred to NMCSD approximately $50 \mathrm{~d}$ after injury.
The patient had sustained three major limb amputations, including right and left transfemoral amputations and a left transhumeral amputation. This patient's ISS was 30 , including a serious right femoral neck fracture (AIS = 3) and several moderate injuries (AIS = 2), particularly soft tissue wounds to the upper thigh/gluteal region caused by perineal/perineum/perirectal penetrating wounds. This resulted in testicular avulsion, rupture, and loss of testicle (via orchiectomy) and loss of right scrotal skin. He had postinjury pain, phantom limb issues, and perineal trauma requiring a colostomy, which was reanastomosed 6 mo postinjury. Following his initial evaluation, he developed significant psychological issues, including anxiety, depression, and family-related problems. These symptoms were closely monitored by the mental health team, which provided proactive support and treatment.

Lower-limb prosthesis management. The patient initiated prosthesis training $104 \mathrm{~d}$ after injury with shortie prostheses with manual locking knees. The guidelines used for lengthening shorties and progression to microprocessor knees were as described previously for Case 1. After approximately 8 wk of training in his shortie prostheses, he transitioned to a conventional prosthesis design with advanced microprocessor knees for both limbs (X2) and multiaxial and dynamic Triton feet (Ottobock USA). These feet were compatible with his K-3 level ability [18] (potential for ambulation with variable cadence-a typical community ambulator with the ability to traverse most environmental barriers). We selected the X2 knee as his initial prosthesis because of his rapid advancement on his shorties and his relatively long residual-limb length, which facilitated ambulation. This device is an advanced version of the C-Leg for people with transfemoral amputation that allows for a more natural gait by facilitating a fluid swing phase and transition for the knee, which includes shock-absorbing capabilities. The device was designed for increased durability and programming to permit flexibility for higher level activities, and it provides the patient with alternative feet components. The patient met ambulation goals at 9 mo postinjury. He used these lower-limb prostheses 12 to $15 \mathrm{~h} / \mathrm{d}$ and was working on advanced mobility tasks (e.g., walking up and down ramps and stairs). He was fitted with running prostheses and participated in adaptive sporting events, including snowboarding.

Upper-limb prosthesis management. The goal of the rehabilitation team was to fit patients with prosthetic devices that patients would use regularly. Body-powered 
prosthetic arm options included (1) an elbow unit with a voluntary open terminal device and (2) a no-elbow unit with a terminal device mounted directly to a custom flexed socket. This configuration is much lighter and can support simple functions including grasping, holding, and writing. Myoelectric options included (1) a full myoelectric elbow unit with a myoelectric terminal device, (2) a hybrid body-powered unit with a myoelectric terminal device, and (3) a no-elbow unit with a myoelectric terminal device mounted directly to a custom flexed socket.

This patient had particularly complex prosthetic challenges because of his transhumeral amputation and bilateral lower-limb amputations. Multiple upper-limb prosthesis trials were performed within the first 3 mo. His upper-limb prosthesis design was developed at the same time as his lower-limb prosthetic designs to optimize independent function. Once he was able to initiate independent ambulation with his lower-limb prosthesis (2-3 mo), his upperlimb prosthesis design was optimized to improve upperbody function for gross motor and fine motor skills. After numerous design trials, he preferred a myoelectric terminal device prosthetic arm solution without an elbow unit. The patient presently uses a Michelangelo Hand (Ottobock USA), a terminal myoelectric carbon fiber prosthetic hand attached directly to the transhumeral socket and suspended with suction and a shoulder harness. The muscles in the upper arm control operation of the prosthetic hand device. This solution was much lighter without an elbow component, and its overall length could be adjusted and customized for individual function through a custom wrist adaptor unit.

At 15 mo postinjury, this patient had met his basic program goals for independent activities of daily living and for functional ambulation. Beyond his functional ambulation goals, he was advancing to a dynamic ambulation skills therapy program that included uneven terrain, ramps, hills, hiking, variable cadence, stair climbing, community/city ambulation skills, and return-to-run and adaptive exercise programs. To develop these advanced skills, he continued regular physical therapy up to five times a week and was ambulatory in a community setting with his advanced hydraulic-based microprocessor X2 knee prostheses during the time he transitioned from medical retirement to civilian life as a student and work intern. He also continued working on goals to be pain free without medication and to drive a vehicle with adaptive modifications. After being awarded medical retirement from military service, he returned to school to pursue an advanced degree.

\section{DISCUSSION}

This clinical report describes the outpatient rehabilitation at NMCSD for patients who sustained multiple limb amputations in the Afghanistan conflict. The casualty records in Expeditionary Medical Encounter Database provide some of the most detailed descriptions to date of the extensive injuries of people with recent multiple limb amputations [2,9]. This report is one of the first to quantify the extensive use of a wide range of rehabilitation clinics by these patients during the first 18 mo after injury. We also described improvements in the patients' physical and psychosocial functioning between program initiation and discharge as assessed by the clinical staff with the MPAI-4. The two case reports illustrate the use of intensive multidisciplinary care, particularly prosthesis care, for combat Veterans with multiple limb amputations.

This report should be considered with a previous clinical report on rehabilitation of similar patients at Walter Reed National Military Medical Center. Many of the rehabilitation methods reported previously (e.g., progression of prosthesis trials) appeared effective for the present sample [3]. This report added detailed description of injuries (Table 1) and quantified clinic use and patient functioning. For the present sample, the results show patients were engaged in daily rehabilitation therapy, particularly over the first 6-9 mo, and approximately several times a week thereafter for 18 mo (Figure 1). The results also show substantial changes in the frequencies of different therapy over time. Overall, the relatively high volume of clinic use over time suggests effective case management to maintain the continuity and timeliness of care.

The functional assessments also were consistent with the program's effectiveness by showing improvements in physical and psychosocial functioning. The providers also noted that the MPAI-4 facilitated discussion at clinical team meetings to obtain consensus of current patient functioning and ongoing updates for each patient's care plan. Importantly, some measures, such as employment, remained unchanged between program initiation and discharge. This finding likely reflects, at least in part, that a patient's primary goal in the first $12-18$ mo postinjury was medical and physical rehabilitation. Most patients 
were just beginning the process of separating from military service and transitioning to civilian life, including developing career goals. We conducted a follow-up search of our databases for records of service discharge through the end of 2015. We found that all 29 patients had service discharge records indicating they had separated from military service. The median time from injury to service discharge was $24 \mathrm{mo}$, with a range of 15 to $50 \mathrm{mo}$. Two patients had reenlistment records prior to eventual discharge. Previous research found that overall only 11 percent of people with major limb amputations remained on Active Duty and 2 percent continued in the same military occupational specialty after amputation [19-20]. A full discussion of issues related to future employment and community reintegration are beyond the scope of this study. This is a critical area for future research [21].

The MPAI-4 results in this report should be interpreted with caution because this instrument has not been validated for patients with amputation. We note that provider assessments of functioning were based on objective events (e.g., ambulation using prostheses for the mobility item, driving an adaptive vehicle for the transportation item, adaptive cycling and swimming for the leisure and recreation item, decreased use of medication for improvements on the pain item). Credentialed mental health professionals on the clinical team assessed psychological issues such as irritability, anxiety, and depression. In a recent review, the MPAI-4 was one of five instruments that captured all functional criteria defined by the International Classification of Functioning, Disability and Health taxonomy for activities and participation [21]. As discussed earlier, the instrument appears to have face and content validity for assessment functioning following amputation. Future work should evaluate the concurrent and/or predictive validity of this instrument to assess functioning following traumatic amputations. It would be particularly useful to develop measures that predict community reintegration based on early postinjury measures of the injuries and physical and psychological assessments during outpatient rehabilitation [21]. The results of this study are also limited to the present sample of military personnel injured in combat and the C5 program.

The case reports illustrated specific and contrasting prosthetic solutions for two individuals with uniquely complex injuries. For Case 1, a patient with high-level and bilateral lower-limb amputations (e.g., hip disarticulation), the advanced Power Knee and C-Legs had limited success and utility. Case 2 had relatively long, bilateral transfemoral amputations and performed adequately and preferred advanced microprocessor knee prostheses [22]. Both case histories illustrated the extensive prosthetic resources available and the wellcoordinated multidisciplinary care received. The case reports also illustrated rejection, or limited use, of upperlimb prostheses. In our experience, functional use of upper-limb prostheses is limited by the overall weight of the device, limited freedom of movement, and difficulty in learning and operating the sensory/motor interface between the residual and prosthetic limb. We note that previous research generally shows that patients report a relatively high prevalence of rejection of upper-limb prostheses [23-24]. The reader is reminded to avoid generalizing from the prosthetic solutions presented in these case reports because they are based on only two individuals. Recent reviews address the functionality and utility of various classes of conventional and technologically advanced prosthetic devices [3,23,25-26]. In general, more research is needed to help identify patient and injury characteristics that predict successful performance for various classes of conventional and technologically advanced devices.

\section{CONCLUSIONS}

This clinical report quantified the extensive injuries and use of outpatient rehabilitation care at one military facility for a small sample of patients who sustained multiple limb amputations in Afghanistan in 2010 and 2011. The functional assessments indicated substantial improvements, particularly in mobility between program initiation and discharge. Two case reports illustrated the coordination and progression of multispecialty care, including contrasting prosthetic solutions for each patient. Future research should validate functional assessment instruments that facilitate clinical care during outpatient rehabilitation and provide metrics for program evaluation. Evaluation of military rehabilitation programs following traumatic amputation can support development of healthcare models for military, Veteran, and civilian medical systems.

\section{ACKNOWLEDGMENTS}

\section{Author Contributions:}

Study concept and design: T. Melcer, J. Pyo, J. Walker. 
Expeditionary Medical Encounter Database and C5 data acquisition: M. Galarneau, K. Quinn, K. Neises, M. Lebedda, C. Nguyen, J. Pyo. Analysis of data: K. Neises, C. Nguyen, M. Lebedda, T. Melcer, J. Walker.

Interpretation of data: T. Melcer, J. Pyo, K. Neises, M. Lebedda, J. Walker.

Drafting of manuscript: T. Melcer, J. Pyo.

Critical revision of manuscript for important intellectual content:

T. Melcer, J. Pyo, J. Walker, K. Quinn, M. Galarneau.

Financial Disclosures: The authors have declared that no competing interests exist.

Funding/Support: This material was based on work was supported by the Navy Bureau of Medicine Wounded, Ill, and Injured Program under work unit N1209.

Additional Contributions: Jay Pyo, DO, is now affiliated with Polytrauma/Amputation Network Site, VA San Diego Healthcare System, San Diego, California. We gratefully acknowledge our ongoing collaborations with NMCSD and specifically providers at the C5 facility at NMCSD. This study, and the manuscript itself, benefited greatly from advice and assistance from the clinicians, epidemiologists, technical writers, database analysts, and programmers working on the Expeditionary Medical Encounter Database project at the NHRC, including Carrie Brown, Mary Clouser, Sue Eskridge, Amber Dougherty, Judy Dye, Natella Feinstein, Peggy Han, Charles Jackson, Hoa Ly, and Gerry Pang. We also thank anonymous individuals who peerreviewed this manuscript.

Institutional Review: The study was approved by the Institutional Review Board at the Naval Health Research Center (protocol NHRC.2011.0034). Of 36 patients who were invited to participate, 29 individuals provided free and informed written consent to have their medical records reviewed.

Participant Follow-Up: The authors have no plans to notify the study subjects of the publication of this article because of a lack of contact information.

\section{REFERENCES}

1. Krueger CA, Wenke JC, Ficke JR. Ten years at war: Comprehensive analysis of amputation trends. J Trauma Acute Care Surg. 2012;73(6 Suppl 5):S438-44.

[PMID:23192067] http://dx.doi.org/10.1097/TA.0b013e318275469c

2. Andersen RC, Fleming M, Forsberg JA, Gordon WT, Nanos GP, Charlton MT, Ficke JR. Dismounted complex blast injury. J Surg Orthop Adv. 2012;21(1):2-7. [PMID:22381504]

3. Harvey ZT, Loomis GA, Mitsch S, Murphy IC, Griffin SC, Potter BK, Pasquina P. Advanced rehabilitation techniques for the multi-limb amputee. J Surg Orthop Adv. 2012; 21(1):50-7. [PMID:22381511]

4. Benfield RJ, Mamczak CN, Vo KC, Smith T, Osborne L, Sheppard FR, Elster EA. Initial predictors associated with outcome in injured multiple traumatic limb amputations: A Kandahar-based combat hospital experience. Injury. 2012;
43(10):1753-8. [PMID:22840556]

http://dx.doi.org/10.1016/j.injury.2012.06.030

5. Mamczak CN, Elster EA. Complex dismounted IED blast injuries: The initial management of bilateral lower extremity amputations with and without pelvic and perineal involvement. J Surg Orthop Adv. 2012;21(1):8-14. [Review]. [PMID:22381505]

6. Caravalho J. Dismounted complex blast injury: Report of the Army Dismounted Complex Blast Injury Task Force. Fort Sam Houston (TX): Dismounted Complex Blast Injury Task Force; 2011. 87 p. Available from:

http://armymedicine.mil/Documents/DCBI-Task-ForceReport-Redacted-Final.pdf

7. Naval Medical Center San Diego. Comprehensive Combat and Complex Casualty Care [Internet], San Diego (CA): U.S. Department of Defense, Bureau of Medicine and Surgery; c2016 [cited 2016 Dec 31]. Available from http:// www.med.navy.mil/sites/nmcsd/pages/care/c5.aspx

8. Department of Veterans Affairs [Internet]. Washington (DC): U.S. Department of Veterans Affairs; c2016. VA/ DoD clinical practice guideline for rehabilitation of lower limb amputation; 2008 Jan [cited 2016 Dec 31]. Available from:

http://www.healthquality.va.gov/amputation/amp sum 508.pdf

9. Galarneau MR, Hancock WC, Konoske P, Melcer T, Vickers RR, Walker GJ, Zouris JM. The Navy-Marine Corps Combat Trauma Registry. Mil Med. 2006;171(8):691-7. [PMID:16933807] http://dx.doi.org/10.7205/MILMED.171.8.691

10. Baker SP, O’Neill B, Haddon W Jr, Long WB. The injury severity score: A method for describing patients with multiple injuries and evaluating emergency care. J Trauma. 1974;14(3):187-96. [PMID:4814394] http://dx.doi.org/10.1097/00005373-197403000-00001

11. Center for Outcome Measurement in Brain Injury [Internet]. San Jose (CA): Center for Outcome Measurement in Brain Injury; c1998-2012. Introduction to the MayoPortland Adaptability Inventory; 2005 [cited 2016 Dec 31]. Available from: http://www.tbims.org/combi/mpai/index.html

12. Kean J, Malec JF, Altman IM, Swick S. Rasch measurement analysis of the Mayo-Portland Adaptability Inventory (MPAI-4) in a community-based rehabilitation sample. J Neurotrauma. 2011;28(5):745-53. [PMID:21332409] http://dx.doi.org/10.1089/neu.2010.1573

13. Malec JF. Comparability of Mayo-Portland Adaptability Inventory ratings by staff, significant others and people with acquired brain injury. Brain Inj. 2004;18(6):563-75. [PMID:15204337] http://dx.doi.org/10.1080/02699050310001646134 
14. Malec JF. The Mayo-Portland Participation Index: A brief and psychometrically sound measure of brain injury outcome. Arch Phys Med Rehabil. 2004;85(12):1989-96.

[PMID:15605338]

http://dx.doi.org/10.1016/j.apmr.2004.01.032

15. Fairbank JC, Pynsent PB. The Oswestry Disability Index. Spine. 2000;25(22):2940-52; discussion 2952. [Review]. [PMID:11074683] http://dx.doi.org/10.1097/00007632-200011150-00017

16. Center for Outcome Measurement in Brain Injury [Internet]. San Jose (CA): Center for Outcome Measurement in Brain Injury; c1998-2012. Introduction to the FIM (TM); 2016 [cited 2016 Dec 31]. Available from:

http://www.tbims.org/combi/FIM/index.html

17. Melcer T, Belnap B, Walker GJ, Konoske P, Galarneau M. Heterotopic ossification in combat amputees from Afghanistan and Iraq wars: Five case histories and results from a small series of patients. J Rehabil Res Dev. 2011;48(1):1-12. [PMID:21328158] http://dx.doi.org/10.1682/JRRD.2010.03.0033

18. American Academy of Orthotists and Prosthetists: Advancing Care Through Knowledge [Internet]. Washington (DC): American Academy of Orthotists and Prosthetists. K-levels; 2016 [cited 2016 Dec 31]. Available from:

http://www.oandp.org/olc/course extended content.asp?frmCourseId=ACA066EC-443A-4822-822C89BC1CBD684E\&frmTermId=k-levels

19. Belisle JG, Wenke JC, Krueger CA. Return-to-duty rates among US military combat-related amputees in the global war on terror: Job description matters. J Trauma Acute Care Surg. 2013;75(2):279-86. [PMID:23887560] http://dx.doi.org/10.1097/TA.0b013e31829bb777

20. Hurley RK Jr, Rivera JC, Wenke JC, Krueger CA. Identifying obstacles to return to duty in severely injured combatrelated servicemembers with amputation. J Rehabil Res Dev. 2015;52(1):53-61. [PMID:26230831] http://dx.doi.org/10.1682/JRRD.2014.04.0094

21. Resnik L, Plow MA. Measuring participation as defined by the international classification of functioning, disability and health: An evaluation of existing measures. Arch Phys Med Rehabil. 2009;90(5):856-66. [PMID:19406308] http://dx.doi.org/10.1016/j.apmr.2008.11.010
22. Penn-Barwell JG. Outcomes in lower limb amputation following trauma: A systematic review and meta-analysis. Injury. 2011;42(12):1474-9. [Review]. [PMID:21831371] http://dx.doi.org/10.1016/j.injury.2011.07.005

23. Resnik L, Meucci MR, Lieberman-Klinger S, Fantini C, Kelty DL, Disla R, Sasson N. Advanced upper limb prosthetic devices: Implications for upper limb prosthetic rehabilitation. Arch Phys Med Rehabil. 2012;93(4):710-7. [PMID:22464092] http://dx.doi.org/10.1016/j.apmr.2011.11.010

24. McFarland LV, Hubbard Winkler SL, Heinemann AW, Jones M, Esquenazi A. Unilateral upper-limb loss: Satisfaction and prosthetic-device use in veterans and servicemembers from Vietnam and OIF/OEF conflicts. J Rehabil Res Dev. 2010;47(4):299-316. [PMID:20803400] http://dx.doi.org/10.1682/JRRD.2009.03.0027

25. Carey SL, Lura DJ, Highsmith MJ; CP; FAAOP. Differences in myoelectric and body-powered upper-limb prostheses: Systematic literature review. J Rehabil Res Dev. 2015;52(3):247-62. [PMID:26230500] http://dx.doi.org/10.1682/JRRD.2014.08.0192

26. Harvey ZT, Potter BK, Vandersea J, Wolf E. Prosthetic advances. J Surg Orthop Adv. 2012;21(1):58-64. [PMID:22381512]

Submitted for publication September 19, 2014. Accepted in revised form June 7, 2016.

This article and any supplementary material should be cited as follows:

Melcer T, Pyo J, Walker J, Quinn K, Lebedda M, Neises K, Nguyen C, Galarneau M. Rehabilitation and multiple limb amputations: A clinical report of patients injured in combat. J Rehabil Res Dev. 2016;53(6):1045-60. http://dx.doi.org/10.1682/JRRD.2014.09.0219

ORCID: Ted Melcer, PhD: 0000-0001-8330-6985

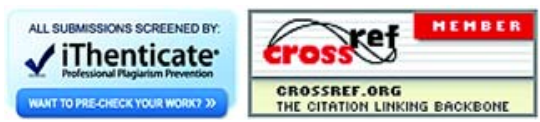

